\title{
Is the Armadale epidemic over? Air pollution and mortality from lung cancer and other diseases, 1961-82
}

\author{
OL LLOYD, FIONA LR WILLIAMS, AND FIONA AY GAILEY \\ From the Environmental Epidemiology and Cancer Centre, Wolfson Institute of Occupational Health, \\ Department of Community Medicine, Unversity of Dundee, UK
}

ABSTRACT In Armadale, a town in central Scotland, the standardised mortality ratios (SMRs) for lung cancer were exceptionally high during 1968-74. A large cluster of cases was found in a residential zone downwind from a foundry. In the present study death certificates in the mortality registers of three town parishes were analysed for 1961-82 and the time trends of mortality from major categories of disease were examined. The distribution of mortality from lung cancer within Armadale's six residential zones was compared with that of the other diseases for the periods 1968-75 and 1976-82; the zone of particular interest was that containing the original cluster of lung cancer. The distribution of lung cancer was also compared with the pattern of air pollution by metals, collected by Sphagnum moss bags. The annual numbers of deaths from respiratory cancer in Armadale rose to a plateau in 1968-77; after a fall during 1978-80, the numbers returned in 1981 and 1982 to their previous high values. Between 1968-75 and 1976-82 the mean SMRs for all of the disease categories except respiratory cancer rose. The SMR for total mortality in 1976-82 was the same as in preceding years when the standardised death rate for Armadale was the highest for Scotland in the annual reports of the Registrar General. In the zone with the highest mortality from lung cancer in 1968-75 the SMR for that disease continued to be higher than expected. That zone also showed the highest SMRs for cancer of the upper alimentary tract, cerebrovascular disease, hypertension, and coronary heart disease; its SMR for bronchitis was the second highest in the town. Pollution studies indicated that zones with high SMRs for respiratory and non-respiratory cancer were exposed to air pollution by metals. The temporal and spatial patterns are consistent with the view that the problem of mortality from cancer and non-malignant diseases in Armadale remains.

Air pollution has been recognised as a possible cause of respiratory cancer, ${ }^{12}$ bronchitis, ${ }^{134}$ and cerebrovascular disease. ${ }^{5}$ Noting statistically significant correlations between various forms of cancer, and between cancer and non-malignant disease, some authors have suggested that common aetiologies might underlie such associations. ${ }^{67}$

In the small burgh of Armadale, central Scotland, the mean standardised mortality ratio (SMR) for respiratory cancer during 1969-73 was the highest in Scotland. ${ }^{8}$ A case-control study indicated that the tobacco habit and occupation had not played a major part in these findings, ${ }^{9}$ but a significantly large number of the cases had resided in a zone of the town

Received 26 February 1985

Accepted 1 April 1985 which was beside and downwind from the local steel foundry. ${ }^{10-12}$ A pilot study of air pollution, using bags of Sphagnum moss to collect airborne metals, showed that the zone received relatively large amounts of atmospheric pollution by metals. ${ }^{10}$ More recently, systematic environmental studies have been undertaken to determine the pattern of pollution throughout the whole town. ${ }^{13-19}$

In the town as a whole during 1968-73 the SMRs for bronchitis, gastic cancer, other non-respiratory cancer, and cardiovascular diseases were also high. ${ }^{820}$ The standardised death rate for all causes of death was the highest of all cities, burghs, and landward areas in Scotland. ${ }^{12}$

This paper reports on three further investigations that were undertaken. Firstly, the temporal patterns of mortality from various diseases in Armadale from 
Table 1 Diseases for which SMRs were calculated

\begin{tabular}{lllc}
\hline Disease & \multicolumn{1}{l}{ ICD code, by appropriate revision } & & \\
\cline { 2 - 4 } & $7 t h$ rev $(1961-7)$ & $8 t h$ rev (1968-75) & 9 th rev (1976-82) \\
\hline 1 Hypertension & $440-443$ & $400-404$ & $400-404$ \\
2 Bronchitis, & $501-502$ & $490-493$ & $490-493$ \\
$\quad$ Emphysema, & 241 & & \\
Asthma & 420 & $410-414$ & \\
3 Coronary heart disease & $330-334$ & $430-438$ & $410-414$ \\
4 Cerebrovascular disease & & 162 & $430-438$ \\
6 Respiratory cancer & & $(140-209)$ minus (162) & 162 \\
7 All deaths minus respiratory cancer & & All minus 162 & $(140-209)$ minus (162) \\
8 Gastric/oesophageal cancer & 151,150 & All minus 162 \\
\hline
\end{tabular}

1961 to 1982 were studied. Secondly, geographical associations were sought between the distributions of mortality from the diseases within zones of Armadale during 1968-75 and 1976-82, with particular emphasis on the zone with the cluster of respiratory cancer during 1968-74. Thirdly, the geographical relation between the distribution of respiratory cancer and that of air pollution was determined through systematic studies using Sphagnum moss bags during 1981-2.

\section{Methods}

For studying the time trends of mortality, the annual numbers of deaths in town from 1961 to 1982 were obtained from the death certificates of the parishes of Armadale and of two nearby towns where the deaths of Armadale residents were sometimes registered. Table 1 shows the diseases studied; following the pro-

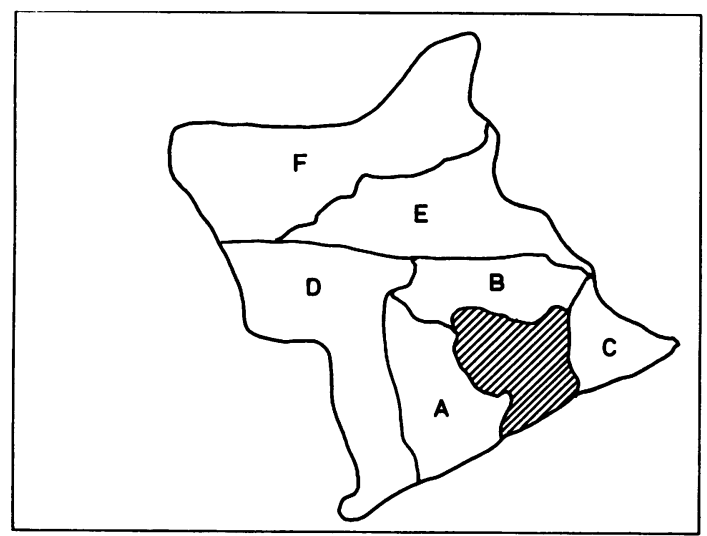

Fig 1 Generalised map of residential area of Armadale with the six zones used in epidemiological analyses for 1968-75 and 1976-82; zones were aggregates of enumeration districts at 1971 or 1981 census respectively; shaded area contained foundry. cedure of the Registrar General the underlying cause of death was selected from the certificate. For the respiratory and non-respiratory cancers, the numbers were calculated for male and female subjects sepa- $\vec{N}$ rately, and for the age groups $0-24,25-64$, and over $\infty$ 64. Mean SMRs for individual diseases and for total $\vec{G}$ mortality were calculated for the periods $1968-75$ and 1976-82.

To ensure that the numbers of deaths from cancer were not the result of excessive coding of cancer for the underlying cause of death in the death certificates, the numbers of certificates with any mention of cancer were also noted. To evaluate the completeness of the collection of deaths from the death certificates, those numbers of deaths were compared with the numbers for the same categories given in the annual reports of the Registrar General for Scotland during 1961-73 (after 1973, the data were not published).

For the spatial analysis, the subdivision of Armadale was based on the zones used previously. ${ }^{10}$ Two periods were investigated, 1968-75 and 1976-82, and hence the zones were based on the enumeration districts of the census years 1971 and 1981 respectively. Despite changes in the enumeration districts at the 1981 census, the zoning for the two periods of study were similar; most of the differences were minor, as for zone A and, to a lesser extent, zones B and C (fig 1).

SMRs.were used as the index of mortality, and calculated for the various categories of mortality (table 8 1) during both periods, for each zone. The numbers of deaths in each zone were obtained by analysing ad- 윽 dresses given on the death certificates. The expected $\rightarrow$ numbers of deaths were derived from the product of the appropriate mean Scottish cause specific death $N$ rates (by five year age group and sex) and the zones' populations at the relevant census year. Confidence $\tilde{O}$ intervals were based on the assumption that the num- N ber of observed deaths in a zone followed a Poisson $O$ distribution. A zone's SMR was regarded as signifi- 0 cantly different from Scotland if the $95 \%$ confidence $\frac{}{\Phi}$ interval for the zone did not include the SMR value of $\stackrel{\mathscr{S}}{?}$ 
Table 2 Annual numbers of deaths of Armadale residents from various categories of disease (A) in the annual reports of the Registrar General for Scotland, and $(B)$ in the death certificates in Armadale burgh and two neighbouring towns

\begin{tabular}{|c|c|c|c|c|c|c|c|c|c|c|}
\hline & \multicolumn{2}{|c|}{ Lung cancer } & \multicolumn{2}{|c|}{$\begin{array}{l}\text { Non-respiratory } \\
\text { cancer }\end{array}$} & \multicolumn{2}{|c|}{ Bronchitis etc } & \multicolumn{2}{|c|}{ Heart disease } & \multicolumn{2}{|c|}{ Cerebrovascular } \\
\hline & $\bar{A}$ & $\bar{B}$ & $\bar{A}$ & $\bar{B}$ & $\bar{A}$ & $\bar{B}$ & $\bar{A}$ & $\bar{B}$ & $\bar{A}$ & $\bar{B}$ \\
\hline $\begin{array}{l}1961 \\
1962 \\
1963 \\
1964 \\
1965 \\
1966 \\
1967 \\
1968 \\
1969 \\
1970 \\
1971 \\
1972 \\
1973 \\
1974 \\
1975 \\
1976 \\
1977 \\
1978 \\
1979 \\
1980 \\
1981 \\
1982\end{array}$ & $\begin{array}{r}2 \\
1 \\
5 \\
3 \\
2 \\
1 \\
2 \\
7 \\
7 \\
8 \\
7 \\
7 \\
10 \\
- \\
- \\
- \\
- \\
- \\
-\end{array}$ & $\begin{array}{l}2 \\
1 \\
4 \\
3 \\
1 \\
1 \\
2 \\
5 \\
7 \\
9 \\
5 \\
6 \\
6 \\
6 \\
4 \\
8 \\
6 \\
3 \\
1 \\
3 \\
4 \\
9\end{array}$ & $\begin{array}{r}10 \\
13 \\
9 \\
5 \\
11 \\
8 \\
13 \\
10 \\
16 \\
15 \\
13 \\
14 \\
14 \\
= \\
= \\
- \\
- \\
= \\
-\end{array}$ & $\begin{array}{r}10 \\
13 \\
6 \\
5 \\
7 \\
6 \\
14 \\
6 \\
9 \\
10 \\
8 \\
12 \\
9 \\
9 \\
7 \\
18 \\
19 \\
14 \\
12 \\
10 \\
9 \\
7\end{array}$ & $\begin{array}{l}4 \\
3 \\
3 \\
0 \\
1 \\
1 \\
4 \\
4 \\
6 \\
4 \\
3 \\
2 \\
4 \\
\\
\\
\text { Z } \\
\text { 二 } \\
\text { Z } \\
\text { - }\end{array}$ & $\begin{array}{l}3 \\
1 \\
4 \\
0 \\
1 \\
1 \\
7 \\
1 \\
8 \\
4 \\
3 \\
3 \\
4 \\
3 \\
2 \\
8 \\
2 \\
7 \\
3 \\
4 \\
2 \\
7\end{array}$ & $\begin{array}{l}17 \\
19 \\
20 \\
12 \\
17 \\
21 \\
19 \\
19 \\
29 \\
17 \\
27 \\
25 \\
36 \\
= \\
- \\
= \\
= \\
= \\
-\end{array}$ & $\begin{array}{r}10 \\
15 \\
14 \\
7 \\
12 \\
20 \\
17 \\
12 \\
20 \\
9 \\
21 \\
15 \\
25 \\
22 \\
17 \\
25 \\
21 \\
19 \\
25 \\
27 \\
34 \\
32\end{array}$ & $\begin{array}{r}8 \\
12 \\
10 \\
14 \\
9 \\
11 \\
8 \\
13 \\
10 \\
14 \\
19 \\
19 \\
13 \\
= \\
- \\
- \\
- \\
-\end{array}$ & $\begin{array}{r}11 \\
12 \\
11 \\
13 \\
9 \\
7 \\
8 \\
10 \\
7 \\
8 \\
12 \\
11 \\
10 \\
14 \\
14 \\
12 \\
19 \\
15 \\
13 \\
14 \\
14 \\
10\end{array}$ \\
\hline
\end{tabular}

100. The zones' SMRs for the various diseases were correlated using Spearman rank order correlation coefficient.

The survey of air pollution took place in 1981 and 1982, and used Sphagnum moss contained in three types of bag (horizontal, vertical, and spherical). At 47 sites throughout the town, bags were exposed for two months each during survey periods lasting for six, 13 , and 17 months for the three types of bag respectively. ${ }^{17}$ The concentrations of iron $(\mathrm{Fe})$, manganese $(\mathrm{Mn})$, and chromium $(\mathrm{Cr})$ in the moss bags were determined by atomic absorption spectrophotometry, and mean values were calculated for individual metals for all sites within each enumeration district of the 1971 census. The Gimms computer

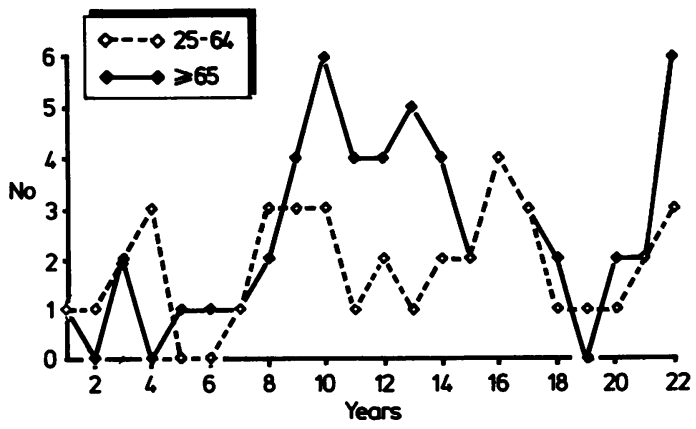

Fig 2 Annual deaths from lung cancer in Armadale, 1961-82, by age group (certificate data). mapping package was used to portray the pattern of metal distribution cartographically. More detailed information about the preparation, deployment, and analysis of the samplers will be described elsewhere but may be obtained from one of us (FAYG).

\section{Results}

Data from the death certificates showed that the annual numbers of deaths from respiratory cancer after 1961 (table 2) were high from 1968 until 1977 and again in 1981-2; deaths were generally in the two older age groups (fig 2) and among men (fig 3). The numbers of deaths for the other diseases rose more gradually from 1961 (table 2). The high numbers for

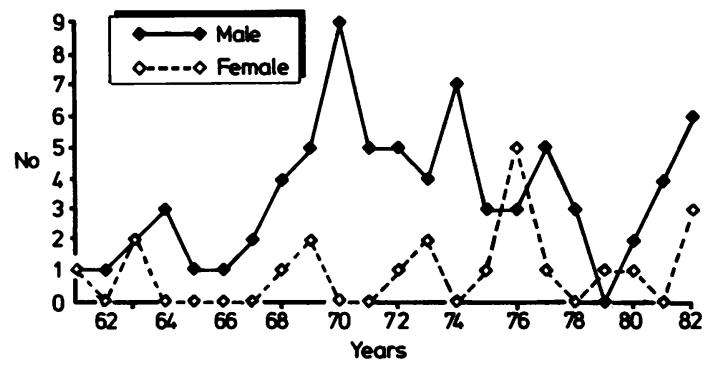

Fig 3 Annual deaths from lung cancer in Armadale, 1961-82, by sex (certificate data). 


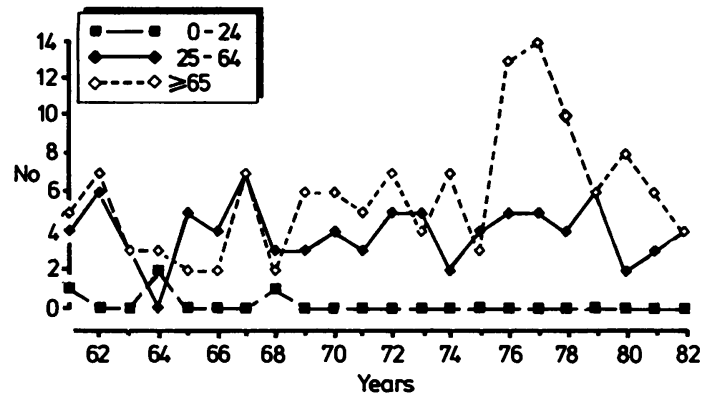

Fig 4 Annual deaths from non-respiratory cancer in Armadale, 1961-82, by age group (certificate data).

non-respiratory cancers in 1976-7 were wholly within the oldest of the three age groups (over 64) (fig 4), with both sexes contributing to that peak (fig 5). During 1961-7, 1968-75, and 1976-82 the annual average numbers of certificates for bronchitis were $2 \cdot 4,3 \cdot 5$, and 4.7; for coronary heart disease they were $13 \cdot 6$, $17 \cdot 6$, and 26.1 ; and for cerebrovascular disease they were 10.1, 10.7, and 13.9. The mean SMRs for the various diseases during the two later periods were: respiratory cancer, 131 and 86 ; non-respiratory cancer, 94 and 104; bronchitis, 109 and 165; ischaemic heart disease, 82 and 106; cerebrovascular disease, 105 and 116; hypertension, 159 and 106; all deaths excluding respiratory cancer, 104 and 108; and total deaths, 105 and 106.

The discrepancies between the numbers of deaths from respiratory cancer and the numbers of deaths with any mention of that disease on the death certificates were negligible - only one extra case being found in each period. There were greater discrepancies between the numbers of deaths from nonrespiratory cancers and the numbers of deaths with any mention of these cancers, 11 in 1968-75 and 12 in

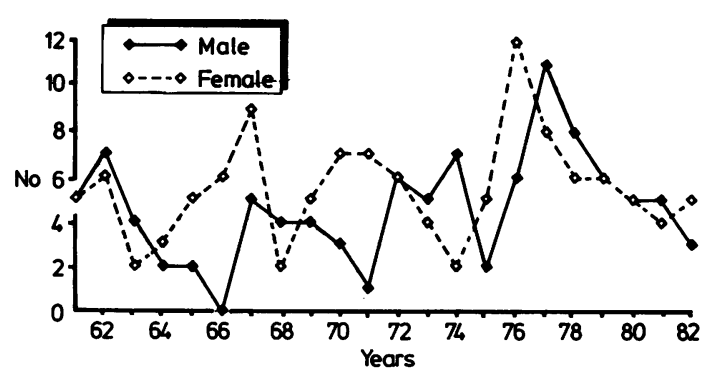

Fig 5 Annual deaths from non-respiratory cancer in Armadale, 1961-82, by sex (certificate data).

1976-82, with the over 64 age group and women accounting for the majority.

During 1961-73, the numbers of deaths obtained from the death certificates for all categories except bronchitis were often appreciably lower than those $\vec{G}$ given in the annual reports (table 2 ).

In general, the SMRs for malignant and nonmalignant diseases (tables 3 and 4) were generally higher in the zones close to the foundry (during both periods) than in the more distant zones. But whereas SMRs for respiratory cancer were high close to the foundry (in zone A), they were also high in zones to the north of the foundry (in zones $\mathrm{E}$ and $\mathrm{F}$ ).

For the zones close to the foundry, the SMRs wee high in zone A more often than in any other zone. seven were above 125; during 1976-82, the SMRs for oesophagogastic cancer and bronchitis in particular were high. In zone B the SMRs for non-respiratory cancer and for bronchitis were high, and the rise in $\frac{D}{\mathbb{D}}$ the SMRs of the three cardiovascular categories resembled that found for zone A. In zone C the SMRs for non-respiratory cancer and for the subgroup of oesophagogastic cancer were raised in both periods,

Table 3 SMRs for malignant neoplasms. (Numbers in parentheses are the observed numbers of deaths)

\begin{tabular}{|c|c|c|c|c|c|c|}
\hline \multirow[t]{2}{*}{ Disease } & \multicolumn{6}{|l|}{ Zone } \\
\hline & $A$ & B & $C$ & $D$ & $E$ & $F$ \\
\hline \multicolumn{7}{|c|}{ Respiratory cancer } \\
\hline $\begin{array}{l}1968-75 \\
1976-82\end{array}$ & $\begin{array}{l}212(16)^{*} \\
112(8)\end{array}$ & $\begin{array}{l}93(7) \\
21(1)\end{array}$ & $\begin{array}{l}76(4) \\
76(3)\end{array}$ & $\begin{array}{r}108(7) \\
71(7)\end{array}$ & $\begin{array}{r}123(7) \\
89(10)\end{array}$ & $\begin{array}{l}157(12) \\
126(9)\end{array}$ \\
\hline \multicolumn{7}{|c|}{ Non-respiratory cancer } \\
\hline $\begin{array}{l}1968-75 \\
1976-82\end{array}$ & $\begin{array}{r}40(7)^{*} \\
109(18)\end{array}$ & $\begin{array}{l}110(22) \\
117(14)\end{array}$ & $\begin{array}{l}166(22)^{*} \\
141(12)\end{array}$ & $\begin{array}{l}78(13) \\
79(18)\end{array}$ & $\begin{array}{r}115(16) \\
91(24)\end{array}$ & $\begin{array}{r}74(14) \\
126(20)\end{array}$ \\
\hline \multicolumn{7}{|c|}{ Gastric/oesophageal cancer } \\
\hline $\begin{array}{l}1968-75 \\
1976-82\end{array}$ & $\begin{array}{r}60(2) \\
213(6)\end{array}$ & $\begin{array}{r}27(1) \\
100(2)\end{array}$ & $\begin{array}{l}290(7)^{*} \\
139(2)\end{array}$ & $\begin{array}{l}32(1) \\
52(2)\end{array}$ & $\begin{array}{l}159(4) \\
181(8)\end{array}$ & $\begin{array}{r}0(0) \\
121(3)\end{array}$ \\
\hline \multicolumn{7}{|c|}{$\begin{array}{l}\text { All causes deaths minus } \\
\text { respiratory cancer }\end{array}$} \\
\hline $\begin{array}{l}1968-75 \\
1976-82\end{array}$ & $\begin{array}{c}97(99) \\
124(124)^{*}\end{array}$ & $\begin{array}{l}95(116) \\
118(86)\end{array}$ & $\begin{array}{r}104(83) \\
93(47)\end{array}$ & $\begin{array}{l}98(98) \\
98(138)\end{array}$ & $\begin{array}{l}141(113)^{*} \\
113(180)\end{array}$ & $\begin{array}{l}98(108) \\
94(81)\end{array}$ \\
\hline
\end{tabular}


Table 4 SMRs for the non-malignant diseases. (Numbers in parentheses are the observed numbers of deaths)

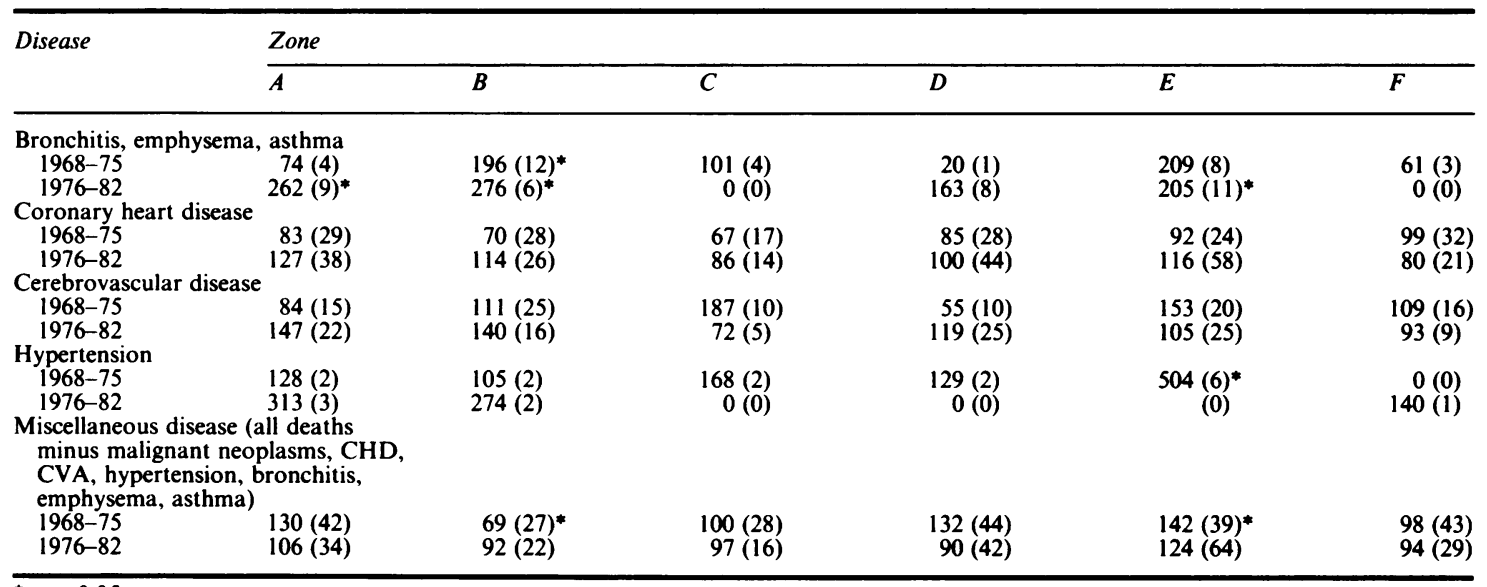

${ }^{*} \mathrm{p}<0.05$.

particularly in the former.

Of the more distant zones, the SMRs in zone D were more consistently low than elsewhere. In zone $\mathrm{E}$ high SMRs were found almost as often as in zone A, six being above 125; diseases with consistently high SMRs were oesophagogastric cancer and bronchitis. In zone $\mathrm{F}$ the SMRs for respiratory cancer were high in both periods, and for non-respiratory cancer in 1976-82.

Striking relations between diseases were noted in zone A. The high SMR for lung cancer during 1968-75 coexisted with low SMRs for a wide range of other diseases; and as that high SMR for lung cancer declined in 1976-82, the mortality from those other diseases (particularly bronchitis and oesophagogastric cancer) rose sharply, so that the SMR for all diseases excluding lung cancer was statistically significant at 124 .

Although none of the correlations between the diseases in the zones (table 5) was statistically significant, some of the associations were noteworthyparticularly the positive correlations between cerebrovascular disease and bronchitis.

The maps of pollution (fig 6) illustrated the areas with high concentrations of $\mathrm{Fe}, \mathrm{Mn}$, and $\mathrm{Cr}$ extending to the east and west from the foundry. High concentrations of $\mathrm{Fe}$ and $\mathrm{Mn}$ were also present north of the foundry.

\section{Discussion}

Mortality from lung cancer in Armadale as a whole declined steeply during the late 1970s, at about the same time as industrial pollution in the town was sharply reduced. This temporal association is consistent with the effects of an environmental pollutant with a short carcinogenic latency (perhaps a pure promoter). Such a mechanism was discussed previously in the context of the onset of the lung cancer epidemic. ${ }^{1120}$ Clearly, the town's mortality must be followed up for some years further, together with repeated environmental monitoring, before the recent rise can be interpreted with confidence as merely a transient or random aberration.

The annual numbers of deaths from all major categories of disease according to the parish death certificates were smaller than the "corrected" numbers given in the annual reports of the Registrar General. The "missing" deaths either may have taken place in hospitals in other districts (the deaths subsequently being registered in those districts) or may have resulted from modification of the death certificate after necropsy. Hence the SMRs calculated in this paper must be taken as underestimates.

In the construction of mortality tables the Registrar General uses the diagnosis given for the underlying cause of death (cause Ic on the death certificate). Although the death certificate may be recoded in certain circumstances, ${ }^{21}$ the coder may be merely reordering chaos if the sequence of the causes of death on the certificate is biologically implausible. In recent years the accuracy of death certification has been frequently discussed. ${ }^{22-26}$ The disagreement between the pathologist's certificate (after necropsy) and the clinical diagnosis has been as high as $39 \% .{ }^{22}$ The divergence of opinion increases with age at death, "especially when neoplasms or cardiovascular or respiratory diseases were thought in life to have been responsible for the last illness." ${ }^{23}$ Although the Reg- 
Table 5 Correlation matrix of various diseases*

\begin{tabular}{|c|c|c|c|c|}
\hline & $\begin{array}{l}\text { Coronary heart } \\
\text { disease }\end{array}$ & $\begin{array}{l}\text { Cerebrovascular } \\
\text { accident }\end{array}$ & $\begin{array}{l}\text { Respiratory } \\
\text { cancer }\end{array}$ & $\begin{array}{l}\text { Non-respiratory } \\
\text { cancer }\end{array}$ \\
\hline $\begin{array}{l}\text { Bronchitis etc } \\
\text { Coronary heart disease } \\
\text { Cerebrovascular disease } \\
\text { Respiratory cancer }\end{array}$ & -0.6 & $\begin{array}{r}1968-75 \\
0.77 \\
-0.37\end{array}$ & $\begin{array}{r}-0.6 \\
0.66 \\
-0.54\end{array}$ & $\begin{array}{r}0.60 \\
-0.43 \\
0.83 \\
-0.83\end{array}$ \\
\hline $\begin{array}{l}\text { Bronchitis etc } \\
\text { Coronary heart disease } \\
\text { Cerebrovascular disease } \\
\text { Respiratory cancer }\end{array}$ & 0.81 & $\begin{array}{r}1976-82 \\
0.87 \\
0.77\end{array}$ & $\begin{array}{l}-0.41 \\
-0.09 \\
-0.20\end{array}$ & $\begin{array}{r}-0.41 \\
-0.54 \\
-0.54 \\
0.20\end{array}$ \\
\hline
\end{tabular}

*Spearman rank order correlation coefficient.

istrar General recodes all certificates in response to information derived from necropsy, necropsies are performed on only about $30 \%$ of deaths in Scotland, and hence the accuracy of the diagnoses on the remaining death certificates is not checked. Nevertheless, the value of death certification in epidemiology is recognised, ${ }^{27}$ for although some diagnoses are completely altered as a result of necropsy, in most cases the revised certificate is only altered by a digit (Registrar General for Scotland, personal communication). Thus for this study where integer ICD units were chosen, the effect of misclassification was mitigated. For Armadale, moreover, the diagnoses of respiratory cancer on the death certificates have been shown to be reliable, $90 \%$ having been confirmed by radiological or histological evidence. ${ }^{28}$

Mortality trends from the other diseases varied during the 1970 s, with increasing values of coronary heart and cerebrovascular diseases, and with generally high values for non-respiratory cancer and bronchitis. It was noted that the SMR for total mortality in Armadale during 1976-82 was similar to that for 1968-75. Since the mean standardised death rate in Armadale during 1969-73 was the highest of any burgh or city in Scotland, ${ }^{12}$ Armadale's SMR in 1976-82 was probably similarly eccentric. (According to the annual reports of the Registrar General the high values for mortality began in 1968.)

Differences between the zones' boundaries at the 1971 and 1981 censuses could have altered the demographic characteristics, and thereby the expected numbers of deaths in those zones for 1968-75 and 1976-82. Effects of altered boundaries and altered demography on the values for expected deaths may be seen in zone B, where 22 deaths in 1968-75 gave an SMR of 110, whereas 14 deaths in 1976-82 gave an SMR of 117. Several diseases in zone $E$ showed similar inconsistencies. In zones $\mathrm{A}$ and $\mathrm{F}$, however, there were no such inconsistencies; furthermore, only minimal changes were observed in the boundaries of zone A (where the large cluster of lung cancer had been found ealier) over the two periods. Hence the continuation into 1976-82 of a high SMR for lung cancer $\stackrel{\vec{N}}{\mathrm{H}}$ in zone $A$, and the sharp rise in the SMRs for other $\vec{N}$ diseases, particularly bronchitis, were not likely to $\infty$ have been affected significantly by demographic arte- $\vec{F}$ fact.

Some of the associations between diseases were of interest. The positive correlations between bronchitis and cerebrovascular disease were in agreement with the strongly positive correlations between air pollution and both bronchitis and cerebrovascular diseases reported by Knox. ${ }^{5}$ The negative correlation between lung cancer and bronchitis, particularly striking iه zones $A$ and $B$, was surprising in view of the share on aetiology of cigarette smoking. Perhaps the effects tobacco had been overriden by the consequences of being exposed to differing qualities ${ }^{1}$ or quantities of air pollution during previous decades.

The value of the study of the associations between the SMRs of the various diseases in the zones was limited by the small number of zones, by their uncertain demographic stability, and by the relatively small numbers of deaths for some diseases on which the SMRs were based.

The high concentrations of $\mathrm{Fe}, \mathrm{Mn}$, and $\mathrm{Cr}$ to the SW and NE of the foundry corresponded with the results of the pilot study, ${ }^{10}$ and were expected from the patterns of the prevailing winds in Scotland. The southwesterlies are the most common but are usually turbulent, whereas northeasterlies are the light winds most frequently associated with temperature in- $\frac{9}{\square}$ versions. ${ }^{29}$ The zones with the high concentrations of $D$ $\mathrm{Fe}$ and $\mathrm{Mn}$, particularly those to the north, were also predictable from the results of a wind tunnel experi- $N$ ment. ${ }^{19}$ This indicated that, with light winds from a wide range of directions, - the pollution from the $\stackrel{\sim}{ }$ foundry flowed westwards or eastwards initially, but $\underset{\omega}{\mathbb{N}}$ was also channelled by local topography downhill and northwards towards the valley in the north of the town.

Because southwesterly winds are generally boister- $\stackrel{?}{+}$ 


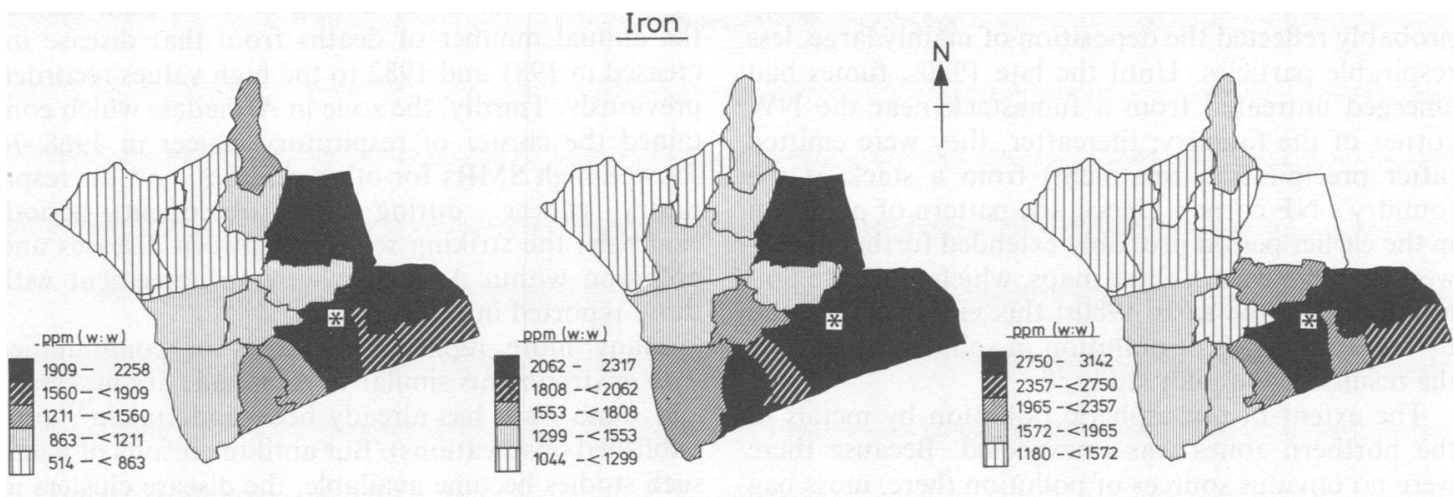

Manganese
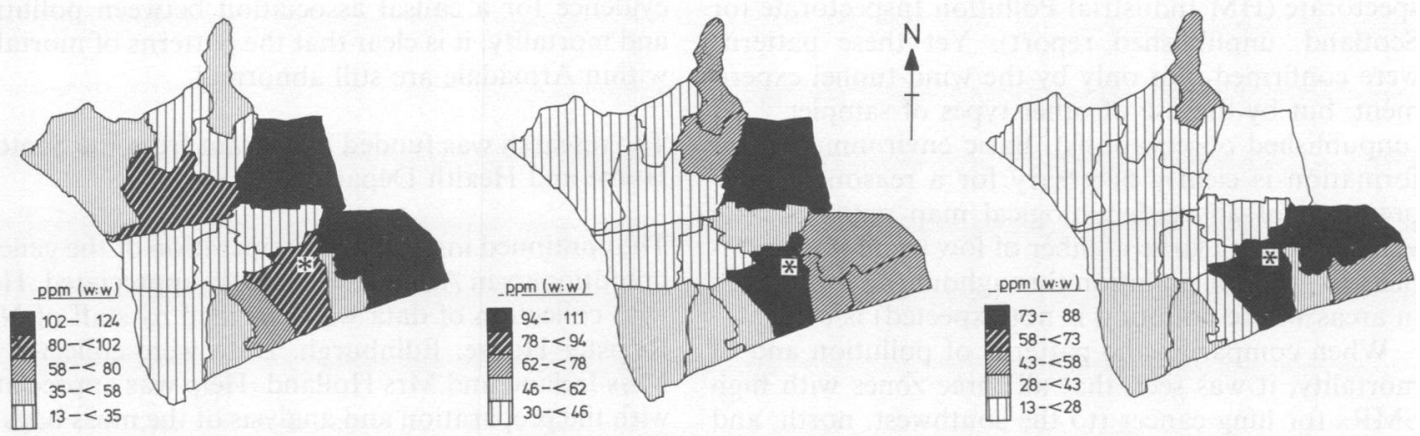

\section{Chromium}

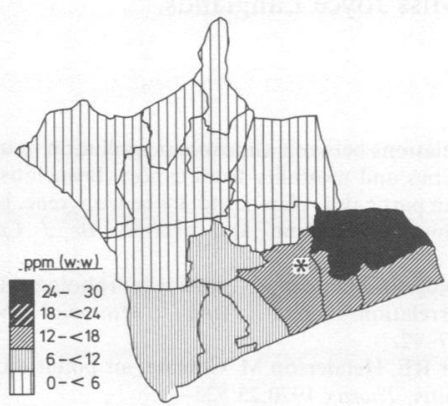

Spherical moss bag

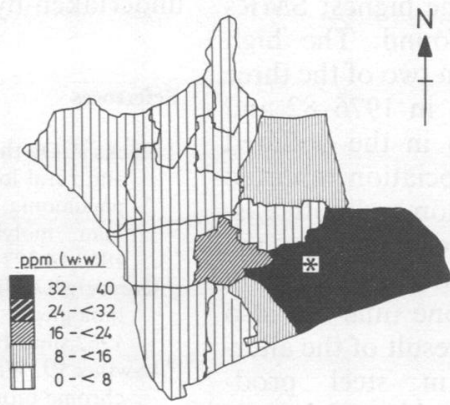

Vertical moss bag

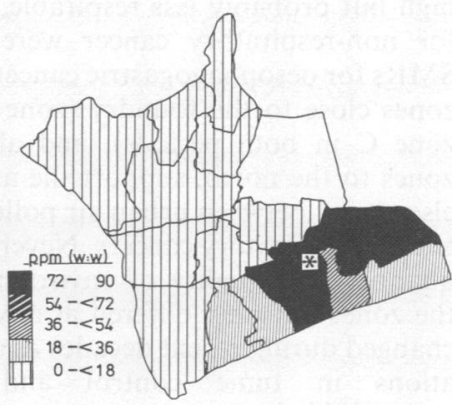

Horizontal moss bag

Fig 6 Concentrations of $\mathrm{Fe}, \mathrm{Mn}$ and Cr collected during varying periods in 1981-2 by spherical, vertical, and horizontal bags containing Sphagnum moss; areas were enumeration districts of 1971 census; (blank area in pattern for horizontal bags indicates data missing through vandalism). 
ous, the high concentrations to the east of the foundry probably reflected the deposition of mainly large, less respirable particles. Until the late 1970 s, fumes had emerged untreated from a fumestack near the NW corner of the foundry; thereafter, they were emitted (after precipitation treatment) from a stack at the foundry's NE corner. Hence, the pattern of pollution in the earlier period probably extended further southwest than appears in these maps, which illustrate pollution during the early 1980s; this view is supported by recent analyses of pollution in soil cores ${ }^{9 \mathrm{a}}$ and by the results of the pilot study. ${ }^{10}$

The extent of atmospheric pollution by metals in the northern zones was unexpected. Because there were no obvious sources of pollution there, moss bag samplers had not been placed there in the pilot study, ${ }^{10}$ nor had conventional samplers in a subsequent survey by the Industrial Pollution Inspectorate (HM Industrial Pollution Inspectorate for Scotland, unpublished report). Yet these patterns were confirmed, not only by the wind-tunnel experiment, but by the use of other types of sampler ${ }^{13-18}$ (unpublished observations). Basic environmental information is clearly necessary for a reasoned interpretation of all epidemiological map patterns. The value of using a large number of low technology samplers to monitor pollution throughout the town (even in areas where pollution is not expected) is evident.

When comparing the patterns of pollution and of mortality, it was seen that all three zones with high SMRs for lung cancer (to the southwest, north, and far north of the foundry) had been exposed to the higher values of air pollution by metals. East of the foundry, where the pollution was most consistently high but probably less respirable, the highest SMRs for non-respiratory cancer were found. The high SMRs for oesophagogastric cancer in two of the three zones close to the foundry (zone A in 1976-82 and zone $\mathrm{C}$ in both periods), and also in the polluted zones to the north, support the association reported elsewhere ${ }^{1}$ between urban air pollution and both gastric and respiratory cancers. Nevertheless, because the quantity and quality of environmental pollution in the zones not only differed at any one time but also changed during recent decades as a result of the alterations in fume control and in steel production, ${ }^{1013-19}$ accurate estimates could not be made about the amount of pathologically relevant pollutants to which residents within each zone had been exposed.

In conclusion then: is the Armadale epidemic over? As answers, several pertinent observations emerged from this study. Firstly, the total mortality in Armadale remained as high during 1976-82 as in preceding years, when its death rate was the highest in Scotland. Secondly, whereas the mean SMR for respiratory cancer there was lower during 1976-82 than earlier, $\frac{2}{2}$ the annual number of deaths from that disease in- $\frac{1}{\mathrm{D}}$ creased in 1981 and 1982 to the high values recorded ? previously. Thirdly, the zone in Armadale which con- $\overrightarrow{7}$ tained the cluster of respiratory cancer in 1968-74 showed high SMRs for other diseases, and for respiratory cancer, during the subsequent period. $\frac{\bar{c}}{\bar{\omega}}$. Fourthly, the striking relation between diseases and $\vec{\sigma}$ pollution within Armadale were in agreement with $\varrho$ those reported in other studies. ${ }^{1530}$ के

Many more replication studies of communities $\vec{\circ}$ with environments similar to Armadale are necessary and some work has already been undertaken ${ }^{31}$ (un- $\vec{\omega}$ published observations). But until the results of many $\frac{}{\circ}$ such studies become available, the disease clusters in $\mathbb{\mathbb { D }}$ Armadale and their associations with pollution require cautious interpretation. Nevertheless, whereas : the present findings alone cannot constitute sufficient $\vec{N}$ evidence for a causal association between pollution $\infty$ and mortality, it is clear that the patterns of mortality $\vec{F}$ within Armadale are still abnormal.

The research was funded by a grant from the Scottish Home and Health Department.

The continued interest and cooperation of the general practitioners in Armadale is greatly appreciated. Help with collection of data was provided by staff of NeQ Register House, Edinburgh. Data were collected or Miss Ireland and Mrs Holland. Help was appreciat with the preparation and analysis of the moss bags Mr G Smith in the laboratory of the Scottish Occupational and Environmental Health Service, Ninewells Hospital, Dundee. Word processing was undertaken by Miss Joyce Langlands.

\section{References}

${ }^{1}$ Stocks $P$. On the relations between atmospheric pollution in urban and rural localities and mortality from cancer, bronchitis and $\mathbb{D}$ pneumonia, with particular reference to 3:4 benzopyrene, beryl- 3 lium, . molybdenum, vanadium and arsenic. $\mathrm{Br} J$ Cancer 1960;14:397-418.

${ }^{2}$ Kreyberg L. Histological lung cancer types: a morphological and biological correlation. Acta Pathol Microbiol Scand 1962;suppl157:7-92.

${ }^{3}$ Lawther PJ, Waller RE, Henderson M. Climate, air pollution, and $O$ chronic bronchitis. Thorax 1970;25:525-39.

${ }^{4}$ Martin AE. Mortality and morbidity statistics and air pollution. $\frac{D}{2}$ Proceedings of the Royal Society of Medicine 1964;57:969-74. ․

${ }^{5} \mathrm{Knox}$ EG. Meteorological associations of cerebrovascular disease $\mathrm{N}$ mortality in England and Wales. $J$ Epidemiol Community Health 1981;35:220-3.

${ }^{6}$ Wynder EL, Hyams L, Shigematsu T. Correlations of international cancer death rates. Cancer 1967;20:113-26.

${ }^{7}$ Levine RS, Witte J. Geographical correlations of colon and breast cancer. Lancet 1984;ii:222.

${ }^{8}$ Lloyd OL, MacDonald J. Continuous epidemiological mapping-a needed public health watchdog. Public Health 1984;98:321-6.

${ }^{9}$ Lloyd OL, Ireland E, Tyrrell HKM, Williams F. Respiratory can- $\stackrel{\mathscr{C}}{+}^{+}$ 
cer in a Scottish industrial community. J Soc Ocup Med (in press).

${ }^{9 a}$ Smith GH, Lloyd OL. Patterns of pollution in soils: a comparison of the values obtained by atomic absorption and $\mathrm{x}$-ray fluorescence. Environmental Toxicology and Chemistry (in press).

${ }^{10}$ Lloyd OL. Respiratory cancer clustering associated with localised industrial air pollution. Lancet 1978; :318-20.

${ }^{11}$ Lloyd OL, Sclare G, Lloyd MM, Yule FA. Respiratory cancer in a Scottish community: some pathological, occupational, and general environmental considerations. In: Grundmann E, Clemmesen J, Muir CS, eds. Cancer campaign 6, cancer epidemiology. Stuttgart: Gustav Fischer Verlag, 1982:103-14.

12 Lloyd OL. Mortality in a small industrial town: problems of analysis and interpretation. In: Ward Gardner A, ed. Current approaches to occupational health. Bristol: John Wright, 1981:283-310.

${ }^{13}$ Yule FA, Lloyd OL. Low technology monitoring of air pollution by metals in relation to the geography of lung cancer. In: Sunderman $\mathrm{FW}, \mathrm{Jr}$, ed. Nickel in the human environment. Lyon: International Agency for Research on Cancer, 1984:253-64. (IARC scientific publications No 53.)

${ }^{14}$ Gailey FA, Lloyd OL. The Use of Lecanora conizaeoides as a monitor of the distribution of atmospheric pollution by metals. Ecology of Disease 1983;3:215-24.

${ }^{15}$ Yule FA, Lloyd OL. Metal content of an indigenous moss in Armadale, central Scotland. Water, Air Soil Pollution 1984;21:261-70.

${ }^{16}$ Yule FA, Lloyd OL. An index of atmospheric pollution survey in Armadale, central Scotland. Water, Air Soil Pollution 1984;22:27-45.

${ }^{17}$ Gailey FAY, Lloyd OL. Grass and surface soils as monitors of atmospheric metal pollution in central Scotland. Water, Air Soil Pollution 1985;24:1-18.

${ }^{18}$ Gailey FAY, Smith GH, Rintoul LJ, Lloyd OL. Metal deposition patterns in central Scotland, as determined by lichen trans- plants. Environmental Monitoring and Assessment (in press).

${ }^{19}$ Gailey FAY, Lloyd OL. A wind tunnel study of the flow of air pollution in Armadale, central Scotland. Ecology of Disease 1983;2:419-31.

${ }^{20}$ Lloyd OL, Barclay R. Hypothesis: a short latent period for respiratory cancer in a susceptible population. Community Med 1979;1:210-20.

${ }^{21}$ World Health Organisation. Manual of the international statistical classification of diseases, injuries and cause of death. Geneva: WHO, 1967.

${ }^{22}$ Black D. Medical aspects of death certification. J R Coll Physicians Lond 1982;16:206-18.

${ }^{23}$ Alderson MR, Bayliss RIS, Clarke CA, Whitfield AGW. Death certification. Br Med J 1983;287:444-5.

${ }^{24}$ Brinkley D, Haybittle JL, Alderson MR. Death certification in cancer of the breast. Br Med J 1984;289:465-7.

${ }^{25}$ Busuttil A, Kemp IW, Heasman MA. The accuracy of medical certificates of cause of death. Health Bull (Edin) 1981; 39: $146-52$.

${ }^{26}$ Percy C, Stanek E, Gloeckler L. Accuracy of cancer death certificates and its effect on cancer mortality statistics. Am J Public Health 1981;71:242-50.

${ }^{27}$ Gardner MJ. Mapping cancer mortality in England and Wales. $\mathrm{Br}$ Med Bull 1984;40:320-8.

${ }^{28}$ Tyrrell HKM, Lloyd OL. The value of death certification for investigating the epidemiology of lung cancer in two Scottish towns 1961-1977. Ecology of Disease 1983;2:235-9.

${ }^{29}$ Meteorological Office. Climatological memorandum 59A. Edinburgh: Meteorological Office, 1969.

${ }^{30}$ Jacobsen BS. The role of air pollution and other factors in local variations in general mortality and cancer mortality. Arch Environ Health 1984;39:306-13.

${ }^{31}$ Lloyd OL, Smith G, Lloyd MM, Holland Y, Gailey FAY. Raised mortality from lung cancer and high sex ratios of births associated with industrial pollution. $\mathrm{Br} J$ Ind $\mathrm{Med}$ 1985;42:475-80. 